\title{
Fructose-induced stress signaling in the liver involves methylglyoxal
}

\author{
Yuren Wei, Dong Wang, Gretchen Moran, Andrea Estrada and Michael J Pagliassotti
}

\begin{abstract}
Background: Fructose produces hepatic insulin resistance in humans and animals. We have proposed that the selective metabolism of fructose by the liver can, under conditions of elevated fructose delivery, inflict a metabolic insult that is localized to the hepatocyte. The present study was designed to identify potential cellular effectors of this insult.

Methods: Primary hepatocytes were incubated with $8 \mathrm{mM}$ glucose and $0.12 \%$ inulin $(\mathrm{G}, \mathrm{n}=6)$ or $8 \mathrm{mM}$ glucose, $0.12 \%$ inulin and $28 \mathrm{mU}$ of inulinase $(\mathrm{GF}, \mathrm{n}=6)$ in the presence or absence of insulin for 0,2 , or $4 \mathrm{~h}$.

Results: GF produced fructose concentrations of $\sim 0.7 \mathrm{mM}$ over the $4 \mathrm{~h}$ experiment. GF induced phosphorylation of MKK7 and JNK, phosphorylation of serine307 on IRS-1, and reduced tyrosine phosphorylation of IRS-1 and -2. GF increased ceramide levels and reactive oxygen species (ROS); however inhibitors of ceramide synthesis or ROS accumulation did not prevent GF-mediated changes in MKK7, JNK or IRS proteins. GF increased cellular methylglyoxal concentrations and a selective increase in methylglyoxal recapitulated the GF-induced changes in MKK7, JNK and IRS proteins.
\end{abstract}

Conclusions: We hypothesize that GF-mediated changes in stress signaling involve methylglyoxal in primary hepatocytes.

Keywords: Sucrose, Insulin resistance, Mitogen-activated protein kinase

\section{Background}

Fructose is an intriguing nutrient due, in part, to its selective hepatic metabolism. The annual per capita consumption of extrinsic or added sucrose and fructose has increased in the US population [1,2]. In rats, diets enriched in sucrose or fructose can produce hepatic insulin resistance independently of changes in body composition [3-5]. Sucrose-induced hepatic insulin resistance occurred concomitantly with elevated hepatic c-jun $\mathrm{NH}_{2}$-terminal kinase (JNK) activity, and normalization of JNK activity in isolated hepatocytes improved insulinstimulated tyrosine phosphorylation of insulin receptor substrate (IRS) proteins and insulin suppression of glucose release [6]. The ingestion of a single, sucrose-enriched meal or elevation of portal vein fructose concentrations via fructose infusion in rats in vivo also increased hepatic JNK activity and phosphorylation of insulin receptor

\footnotetext{
* Correspondence: michael.pagliassotti@colostate.edu

Department of Food Science and Human Nutrition, Colorado State University, 234 Gifford, Fort Collins, CO 80523-1571, USA
}

substrate-1 (IRS-1) on serine ${ }^{307}$, a downstream target of JNK [6]. Fructose infusions in humans can also induce hepatic insulin resistance [7]. The mechanisms leading to these changes remain unclear.

We have proposed that the selective metabolism of fructose by the liver can, under conditions of elevated fructose delivery, inflict a metabolic insult that leads to insulin resistance and involves the hepatocyte [8]. The aim of the present manuscript was to identify potential cellular effectors that mediate fructose-induced activation of stress signaling (JNK) and insulin resistance. Candidate mediators included ceramide, reactive oxygen species and methylglyoxal all of which can activate JNK and accumulate in the context of excessive carbohydrate metabolism [8-11].

\section{Materials and methods Materials}

Glucose, inulin, inulinase, insulin, and methylglyoxal were purchased from Sigma Chemical Co (St. Louis,

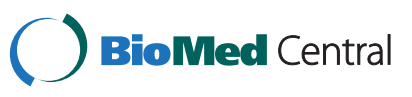

(c) 2013 Wei et al.; licensee BioMed Central Ltd. This is an Open Access article distributed under the terms of the Creative Commons Attribution License (http://creativecommons.org/licenses/by/2.0), which permits unrestricted use, distribution, and reproduction in any medium, provided the original work is properly cited. 
MO). Primary antibodies were purchased from Cell Signaling (Beverly, MA).

\section{Animals}

Male Wistar Crl:(WI)BR rats (Charles River Laboratories, Wilmington, MA) weighing 120-150 grams were provided free access to a purified high-starch diet (Research Diets, Inc, New Brunswick, NJ) for 1 week. All procedures were reviewed and approved by the Colorado State University institutional animal care committee.

\section{Hepatocyte isolation and culture}

Hepatocytes were isolated from rats by collagenase perfusion [12]. Viability, based on trypan blue exclusion, was > 90\%. Cells were first incubated with Roswell Park Memorial Institute media (RPMI) 1640 containing $11 \mathrm{mmol} / \mathrm{L}$ glucose, $10^{-7} \mathrm{~mol} / \mathrm{L}$ dexamethasone, $10^{-7} \mathrm{~mol} / \mathrm{L}$ insulin on collagen-coated plates containing 5\% FBS for $4 \mathrm{~h}$. Following attachment, the media was changed to one containing
RPMI, $8 \mathrm{mmol} / \mathrm{L}$ glucose, $10^{-7} \mathrm{~mol} / \mathrm{L}$ dexamethasone, and $10^{-8} \mathrm{~mol} / \mathrm{L}$ insulin. The following morning media was replaced by RPMI containing glucose but not dexamethasone or insulin. After a $4 \mathrm{~h}$ period, experimental treatments were performed in the absence or presence of insulin. Each experiment was performed in triplicate.

\section{Experimental model}

To perform these studies, a fructose regenerating system developed by Phillips et al. [13] was employed. In brief, inulinase and inulin were used to generate fructose at a rate designed to match fructose utilization. This delivery system minimizes disturbances in ATP and redox status that result from exposing cells to high concentrations of fructose or to nutrient limitation which can easily occur with fructose $[6,14,15]$. Primary rat hepatocytes were incubated with $8 \mathrm{mM}$ glucose and $0.12 \%$ inulin $(\mathrm{G}, \mathrm{n}=6)$ or $8 \mathrm{mM}$ glucose, $0.12 \%$ inulin and $28 \mathrm{mU}$ inulinase $(\mathrm{GF}, \mathrm{n}=6)$ in the absence or presence of $1 \mathrm{nM}$ insulin

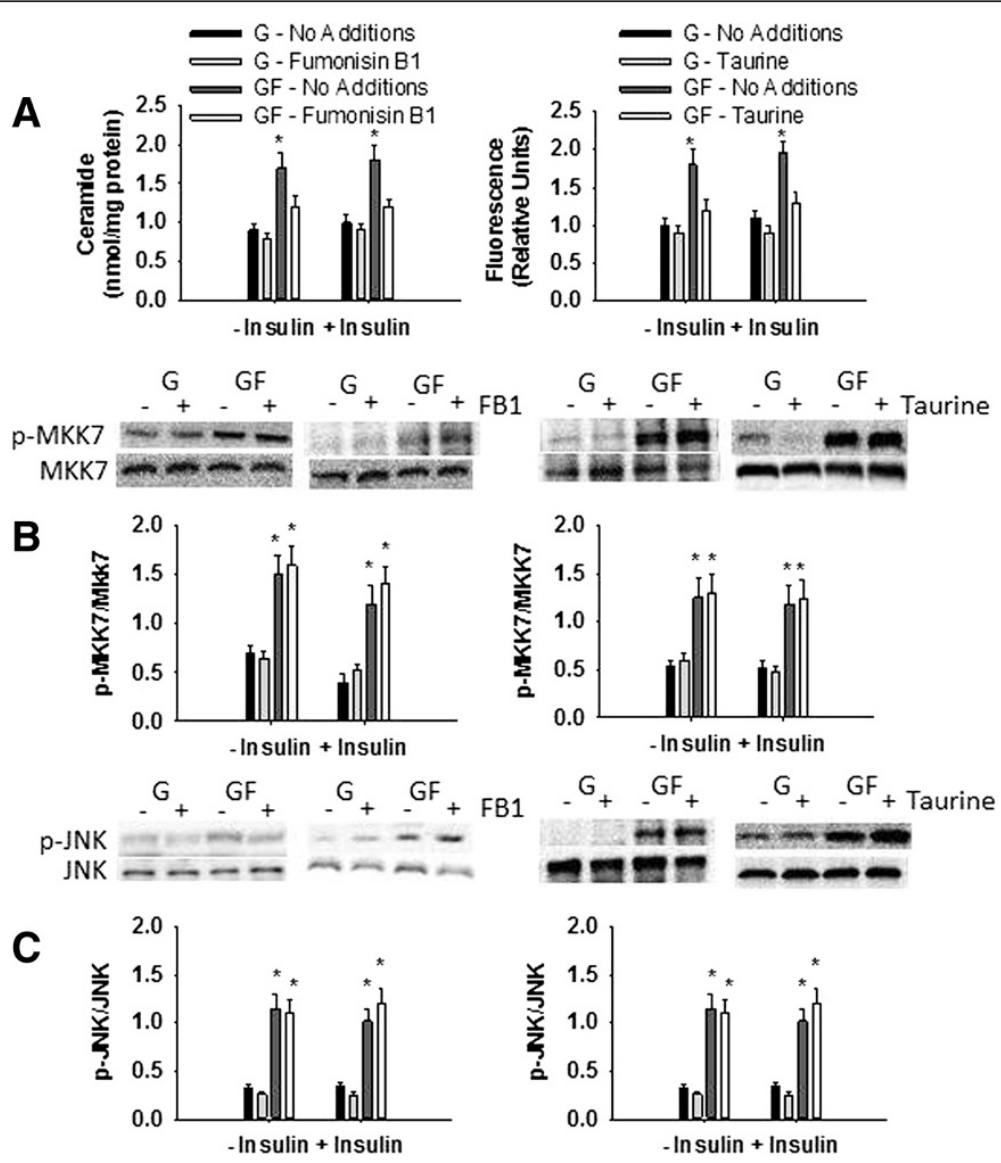

Figure 1 Role of ceramide and oxidative stress in fructose-mediated stress signaling. Ceramide (left) or DCF fluorescence (right) (A), phosphorylation of MKK7 (B), and phosphorylation JNK (C) in primary hepatocytes in response to glucose (G) or glucose and fructose (GF) in the absence (- insulin) or presence (+ insulin) of insulin. When present fumonisin B1 was at $50 \mathrm{uM}$ and taurine at $1 \% \mathrm{~W} / \mathrm{v}$. Data in graphs are the mean \pm SDEV for 6 independent experiments performed in triplicate. Experiments were $4 \mathrm{~h}$ in duration. ${ }^{*}$ significantly different from $\mathrm{G}(p<0.05)$. 
for 0,2 , or $4 \mathrm{hrs}$. In studies utilizing methylglyoxal in the media (MG, $\mathrm{n}=6$ ) incubations were performed with $8 \mathrm{mM}$ glucose, $0.12 \%$ inulin, and methylglyoxal in the absence or presence of $1 \mathrm{nM}$ insulin for $4 \mathrm{hrs}$.

\section{Media analyses}

Glucose and fructose concentrations were determined using standard enzymatic procedures [16]. Methylglyoxal was measured by an o-phenylenediamine (PD) method [17]. Perchloric acid-precipitated samples were supplemented with $100 \mathrm{mM}$ o-PD and the quinoxaline derivative of methylglyoxal (2-methylquinozaline) and the quinoxaline internal standard (5-methylquinoxaline) were then measured by high-performance liquid chromatography (Millipore).

\section{Immunoprecipitation and western blot analysis}

Cells were processed using previously described procedures [6]. Immunoprecipitation of IRS-1 and IRS-2 was performed using Dynabeads Protein G (Novex, Life Technologies). Briefly, equivalent amounts of protein were incubated with antibodies against IRS-1 or IRS-2 followed by incubation with Dynabeads Protein G. Western blot analysis for IRS-1, IRS-2 and tyrosine phosphorylation of IRS-1 and IRS-2 proceeded as described below. Equal amounts of immunoprecipitate or protein
A
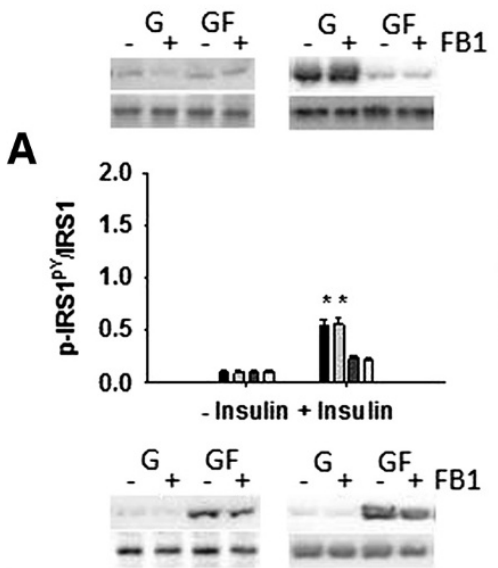

B
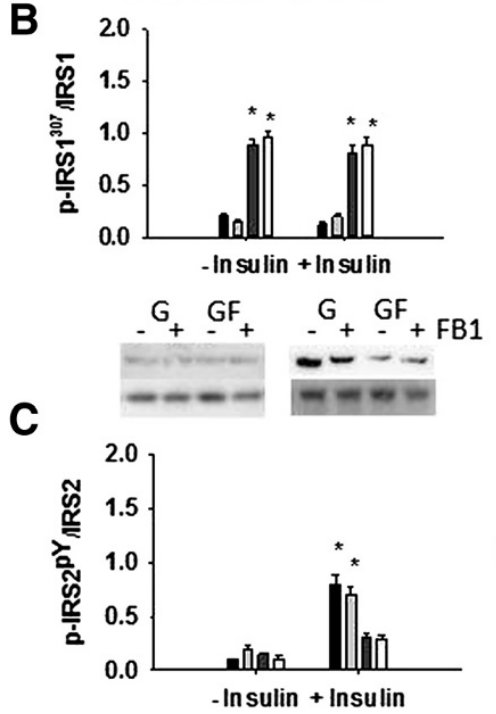
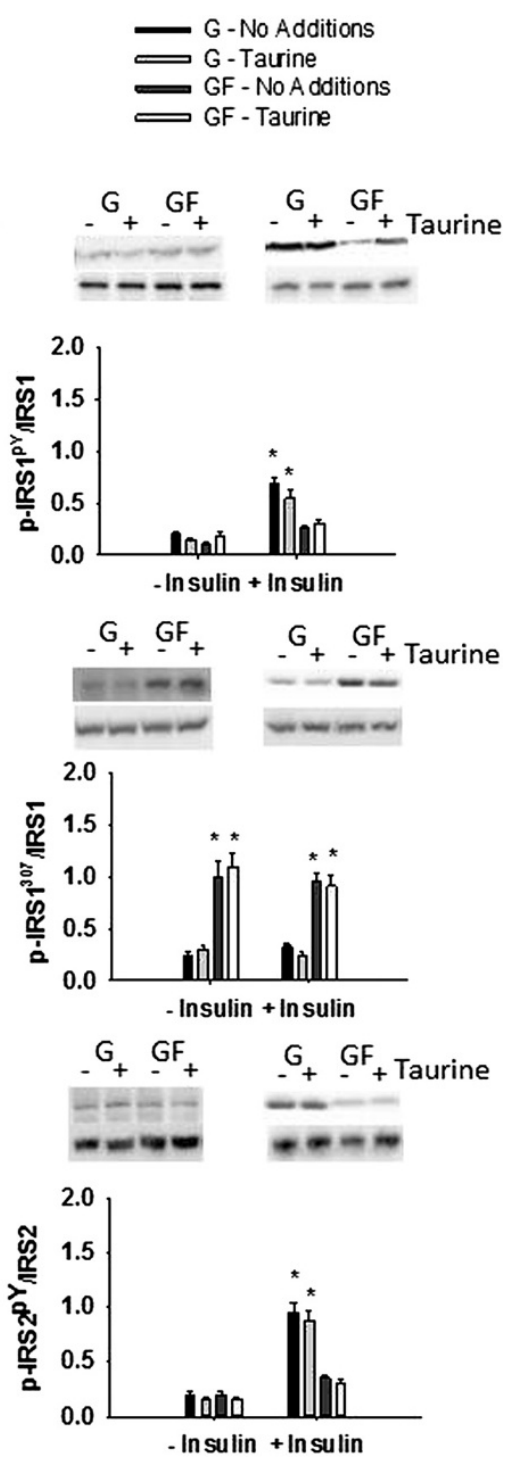

Figure 2 Role of ceramide and oxidative stress in fructose-mediated insulin signaling. Tyrosine phosphorylation of IRS1 (A), phosphorylation of serine 307 on IRS1 (B), and tyrosine phosphorylation IRS2 (C) in primary hepatocytes in response to glucose (G) or glucose and fructose (GF) in the absence (- insulin) or presence (+ insulin) of insulin. When present fumonisin B1 (left) was at $50 \mathrm{uM}$ and taurine (right) at 1\% W/V. Data in graphs are the mean \pm SDEV for 6 independent experiments performed in triplicate. Experiments were $4 \mathrm{~h}$ in duration. * significantly different from $\mathrm{G}(\mathrm{p}<0.05)$. 
were separated by SDS-PAGE, electrotransferred to Hybond-P membranes and membranes incubated with the antibodies described in the Results section. Detection was performed using enhanced chemiluminescence reagents (Santa Cruz Biotechnology, Santa Cruz, CA) and band intensity was analyzed by optical density (UVP Bioimaging system, Upland, CA).

\section{Analysis of Akt}

Total and phosphorylated (serine 473) Akt was determined using the STAR (Signal Transduction Assay Reaction) ELISA kit (Millipore) per the manufacturer's instructions. This kit is based on a solid phase sandwich enzyme-linked immunosorbent assay in which 96-well plates are coated with a monoclonal Akt antibody and following incubation with cell lysates Akt is detected using a specific rabbit anti-Akt1 antibody or phosphorylated Akt is detected using a specific rabbit anti-phospho-Akt (Ser473) antibody.

\section{Oxidative stress}

2,7-dichlorofluorescein di-acetate (DCFH-DA) fluorescence was used to estimate oxidative stress $[18,19]$. Following treatment, cells were loaded with $5 \mu \mathrm{M}$ DCFH-DA (Molecular Probes) using serum free media for $45 \mathrm{~min}$ at $37^{\circ} \mathrm{C}$. Fluorescence was monitored with excitation and emission wavelengths of 490 and $535 \mathrm{~nm}$, respectively. Data are reported as the fold increase in median fluorescence over control cells.

\section{Ceramide}

Ceramide was determined by a modification of the diacylglycerol kinase assay using $\left[\gamma^{-32} \mathrm{P}\right]$ ATP and quantitation of the radioactive spot corresponding to ceramide- 1-phosphate $[20,21]$.

\section{Statistical analysis}

All data are reported as the mean \pm standard deviation. Two-way repeated measures ANOVA was used for data analysis with post-hoc analyses that included linear contrasts and Student-Newman-Keul's test. An $\alpha$-level of $\mathrm{p}<0.05$ was used for statistical significance.

\section{Results}

Role of ceramide and oxidative stress in fructosemediated stress signaling

The fructose regenerating system resulted in stable fructose concentrations of $0.66 \pm 0.08 \mathrm{mM}$ over the course of the $4 \mathrm{~h}$ experiment. Ceramide and reactive oxygen species can activate JNK [22-25]. Fructose delivery (GF) increased ceramide concentration and oxidative stress (Figure 1). Prevention of the fructosemediated increase in ceramide or oxidative stress, using fumonisin B1 or taurine, respectively, did not mitigate the phosphorylation of MKK-7, JNK or serine ${ }^{307}$ of IRS-1 (Figures 1 and 2). In addition, the presence of fumonisin B1 or taurine did not increase insulinstimulated tyrosine phosphorylation of IRS-1 or IRS-2 (Figure 2) or phosphorylation of Akt (Figure 3).
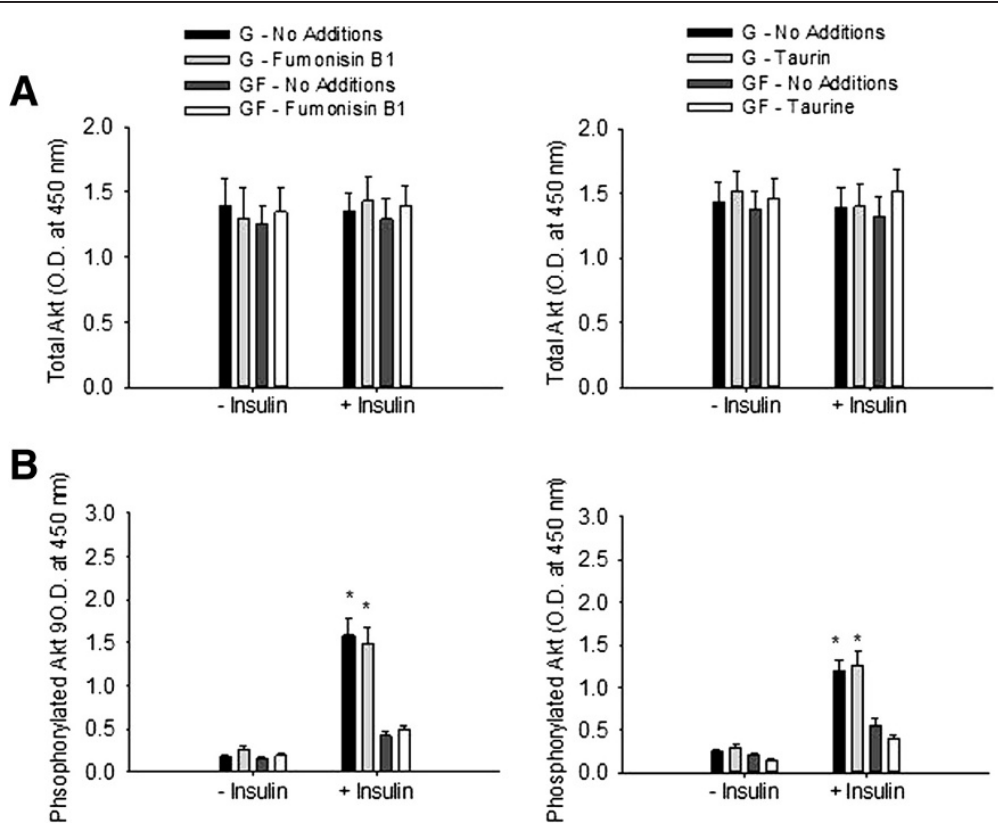

Figure 3 Role of ceramide and oxidative stress in fructose-mediated phosphorylation of Akt. Total (A) and phosphorylated (serine 473) (B) Akt in primary hepatocytes in response to glucose (G) or glucose and fructose (GF) in the absence (- insulin) or presence (+ insulin) of insulin. When present fumonisin B1 (left) was at $50 \mathrm{uM}$ and taurine (right) at $1 \% \mathrm{w} / \mathrm{v}$. Data in graphs are the mean \pm SDEV for 6 independent experiments performed in triplicate. Experiments were $4 \mathrm{~h}$ in duration. ${ }^{*}$ significantly different from $\mathrm{G}(\mathrm{p}<0.05)$. 


\section{Fructose-mediated changes in methylglyoxal}

Fructose delivery (GF) increased methylglyoxal concentrations by approximately $100 \%$ in the absence or presence of insulin at both 2 and $4 \mathrm{~h}$ (Figure 4). In separate experiments primary hepatocytes were incubated with varying concentrations of methylglyoxal in the media in order to determine what media concentration elicited a similar cellular methylglyoxal concentration to that observed with fructose (i.e. $\sim 2 \mathrm{nmol} /$ mgprotein). A media methylglyoxal concentration of $20 \mathrm{uM}$ resulted in liver cell methylglyoxal concentrations of $\sim 2 \mathrm{nmol} / \mathrm{mg}$ protein (Figure 4).

\section{Methylglyoxal recapitulates the effects of fructose on stress signaling}

Incubation of primary hepatocytes with methylglyoxal (media concentration of $20 \mathrm{uM}$ ) for $4 \mathrm{~h}$ increased the

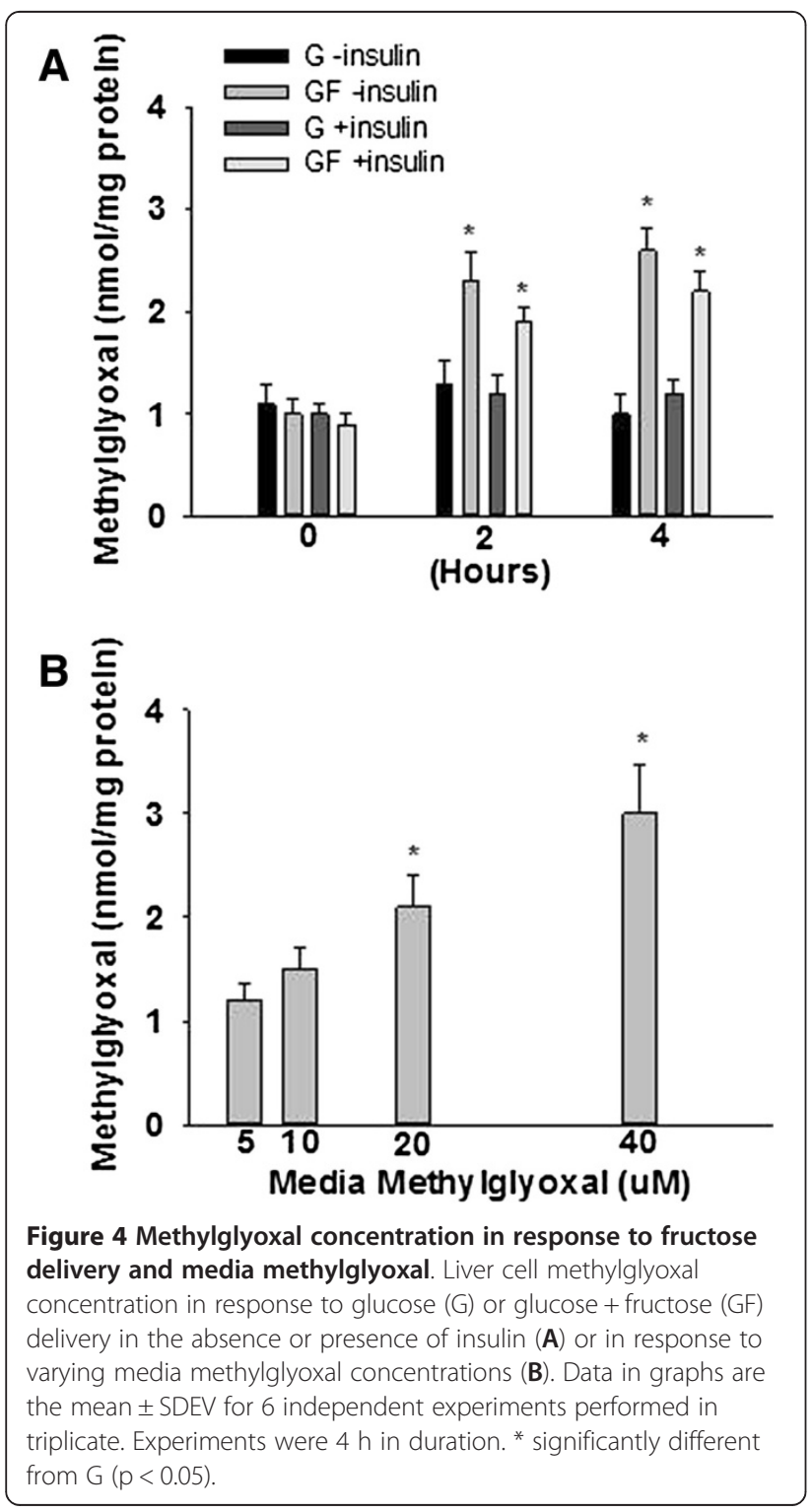

phosphorylation of MKK7, JNK and serine ${ }^{307}$ of IRS-1 in the absence and presence of insulin (Figure 5). Methylglyoxal also reduced insulin-stimulated tyrosine phosphorylation of IRS-1 and IRS-2 (Figure 5).

\section{$\mathrm{N}$-acetyl cysteine (NAC) reduces methylglyoxal and fructose-mediated stress signaling}

NAC is an antioxidant and methylglyoxal scavenger $[26,27]$. Incubation of primary hepatocytes with NAC over a $4 \mathrm{~h}$ period reduced fructose- and methylglyoxal-mediated increases in methylglyoxal, phosphorylation of MKK7, JNK and serine ${ }^{307}$ of IRS-1 in the absence and presence of insulin (Figure 6). The presence of NAC also increased tyrosine phosphorylation of IRS-1 and IRS-2 (Figure 6), and phosphorylation of Akt (Figure 7).

\section{Discussion}

The present study, similar to our previous studies [6], demonstrates that increased fructose delivery activates MKK7 and JNK, and modifies the phosphorylation state of IRS-1 in rat primary hepatocytes. New data demonstrate that fructose delivery increased liver cell methylglyoxal concentrations within a time frame consistent with modifications in the phosphorylation state of MKK7, JNK and IRS-1. In addition, selective elevation of cellular methylglyoxal concentrations recapitulated the effects of fructose on these proteins. Finally, when the increase in methylglyoxal was prevented using $\mathrm{N}$-acetyl cysteine, fructose-mediated changes in stress and insulin signaling were reduced. These data are consistent with the notion that acute effects of fructose delivery on stress signaling may be mediated by changes in cellular methylglyoxal.

Fructose delivery to and metabolism in the hepatocyte generates a signal that culminates in the activation of JNK, phosphorylation of serine ${ }^{307}$ of IRS-1 and reduced insulin-stimulated tyrosine phosphorylation of IRS-1 and IRS-2 [6]. We have hypothesized that this response to fructose delivery results from the burden of fructose metabolism [28]. However, the intrahepatic signal(s) that mediate fructose-induced stress signaling and modulation of insulin signaling have not been identified. In the present study, we examined three potential intrahepatic signals that can promote JNK activation and modulation of IRS-1 phosphorylation; ceramide, oxidative stress and methylglyoxal $[11,23,25,29]$. Although fructose delivery increased all three of these signals, inhibition of the increase in ceramide using fumonisin B1, or oxidative stress, using taurine, did not reduce fructose-mediated effects on stress or insulin signaling. In contrast, experiments in which cellular methylglyoxal concentrations were selectively elevated to levels observed with fructose delivery resulted in the activation of stress signaling and reductions in insulin signaling. In addition, the presence of $\mathrm{N}$-acetyl cysteine, which effectively reduced cellular methylglyoxal concentrations, 


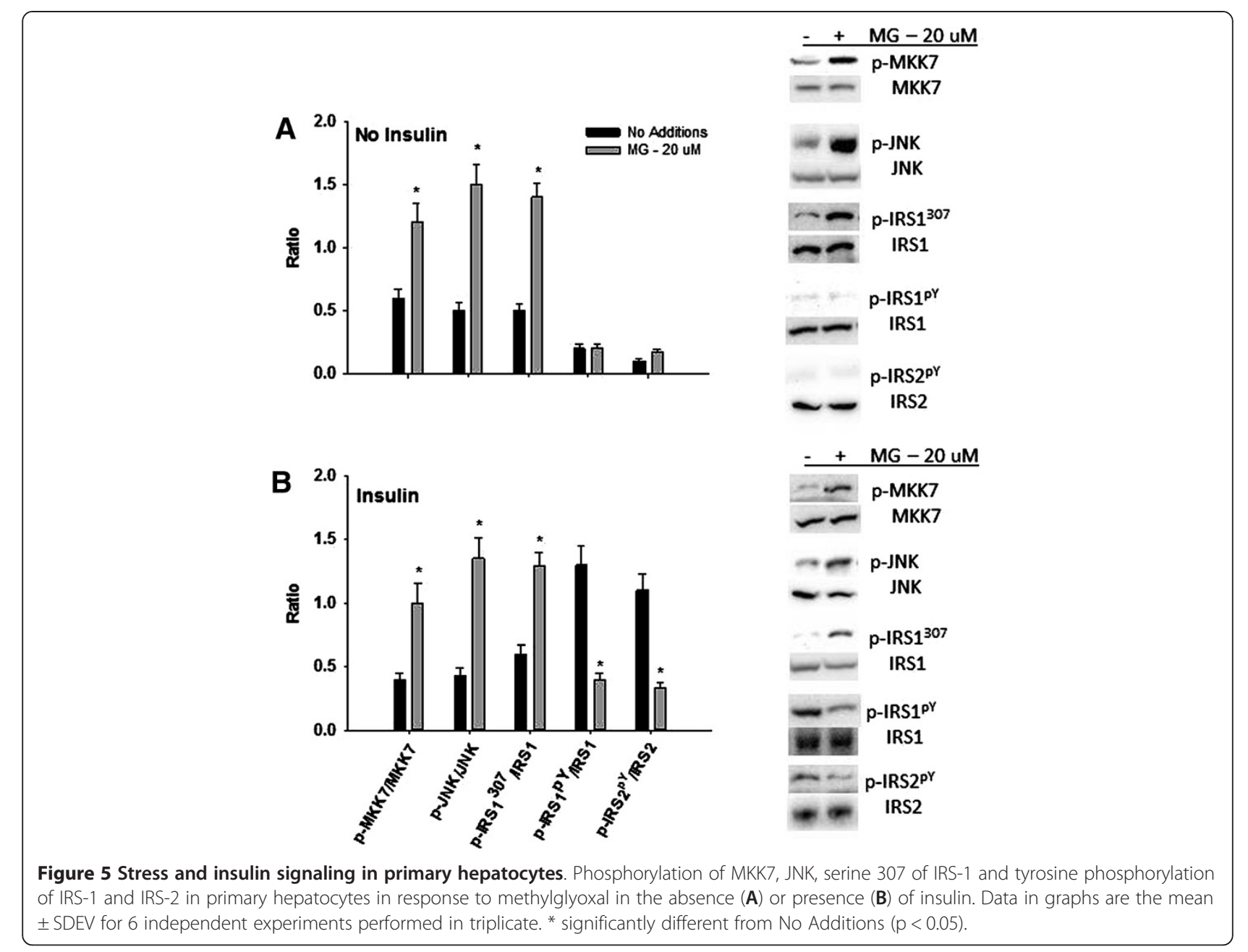

reduced fructose- and methylglyoxal-mediated effects on stress and insulin signaling. These data are consistent with the notion that acute effects of fructose delivery on hepatocyte stress and insulin signaling are mediated by methylglyoxal.

Increased methylglyoxal concentrations have been observed in patients with diabetes and have been associated with progression of diabetic nephropathy [30]. Metformin, which has been used to lower elevated methylglyoxal concentrations in type 2 diabetic patients, was also able to prevent the development of sucrose-induced insulin resistance in rats [31,32]. Increased methylglyoxal has also been linked to impairments in insulin signaling in adipose tissue of fructose-fed rats [33]. Thus, several studies have suggested a link between the accumulation of methylglyoxal and glucose homeostasis.

Methylglyoxal can interact readily with certain arginine and lysine residues in proteins, leading to increased glycation of proteins and advanced glycation end products, such as Nepsilon-carboxyethyl-lysine and $\mathrm{N}$-epsilon carboxymethyllysine $[34,35]$. In vascular smooth muscle cells, very high fructose concentrations (15 mM) increased methylglyoxal and peroxynitrite production, which was inhibited by reactive oxygen scavengers such as reduced glutathione or $\mathrm{N}$ acetyl-l-cysteine [34]. In the present study, although fructose increased DCF fluorescence, amelioration via taurine did not result in a reduction of fructose-mediated stress signaling. Thus, the acute effects of fructose on methylglyoxal concentrations and fructose-mediated changes in stress and insulin signaling may operate independently of oxidative stress. It is important to emphasize that $\mathrm{N}$-acetyl cysteine can act as both an anti-oxidant and a methylglyoxal scavenger [26,27].

Increased fructose consumption and therefore delivery appears to have multiple effects in vivo. Our data suggest that fructose may have rapid, direct effects on the liver that activate stress signaling pathways and reduce insulin signaling. We propose that these effects are largely mediated by local metabolism of fructose in the hepatocyte and perhaps generation of methylglyoxal. Future studies are needed to understand whether and how methylglyoxal mediates these fructose-induced changes. These hepatocyte-specific effects of fructose likely also contribute to lipid accumulation 


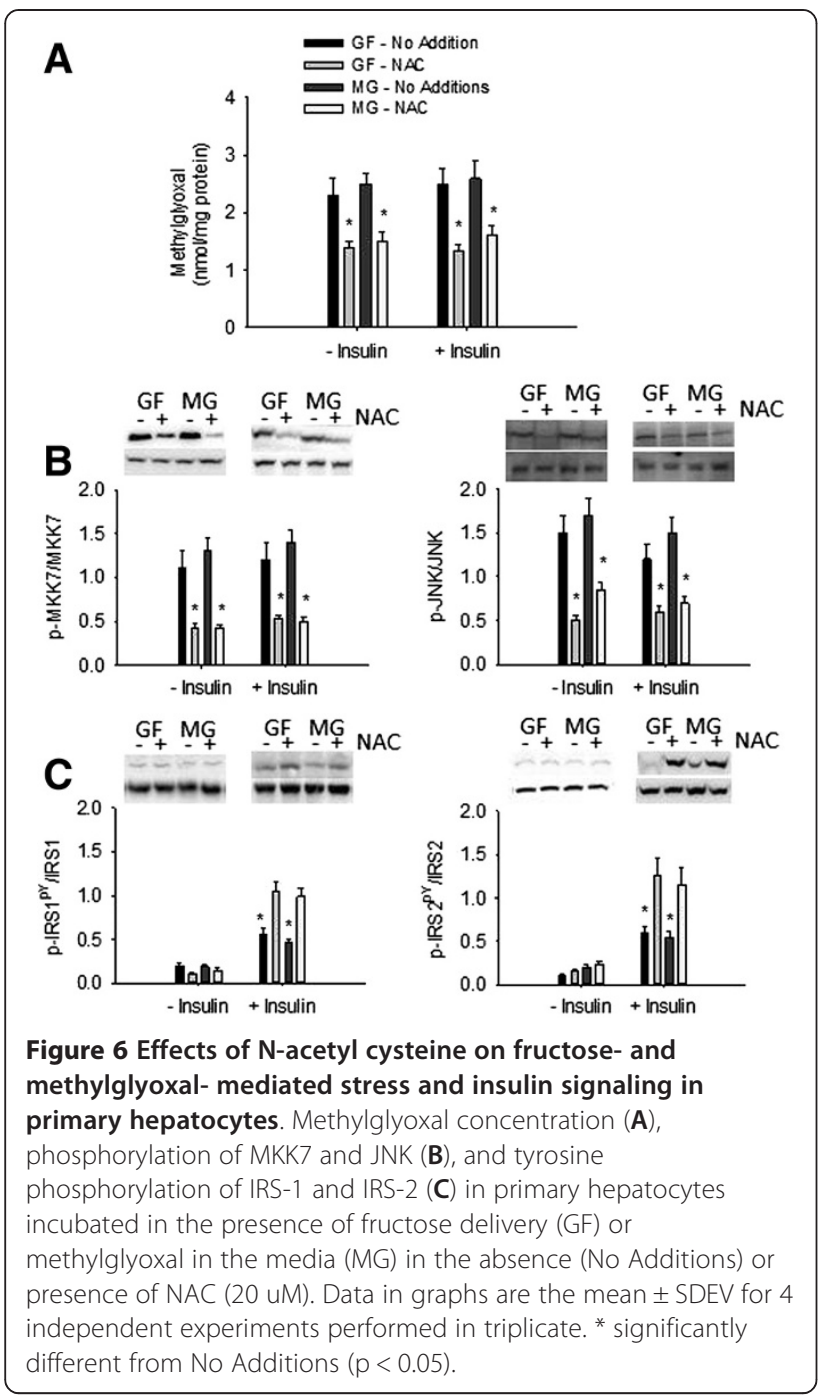

within the hepatocyte [3]. Recent studies have also demonstrated that fructose consumption in beverages or water can lead to accumulation of visceral fat and changes in intestinal barrier function [36,37]. Thus, overconsumption of sucrose and fructose can lead to adaptations in multiple organ systems. However, the quantitative contribution of sucrose and fructose consumption in foods and beverages to human metabolic diseases such as the metabolic syndrome and non-alcoholic fatty liver diseases remains unclear.

The cell system used in the present study, although offering several advantages, does not mimic the dynamic nature of in vivo dietary nutrient delivery. With this in mind, this cellular system was employed only after studies that demonstrated that diets enriched in sucrose or fructose, or fructose infusion in rats in vivo, increased stress signaling and reduced insulin signaling in the liver in vivo $[3,6,38]$. It is likely that the magnitude of hepatic

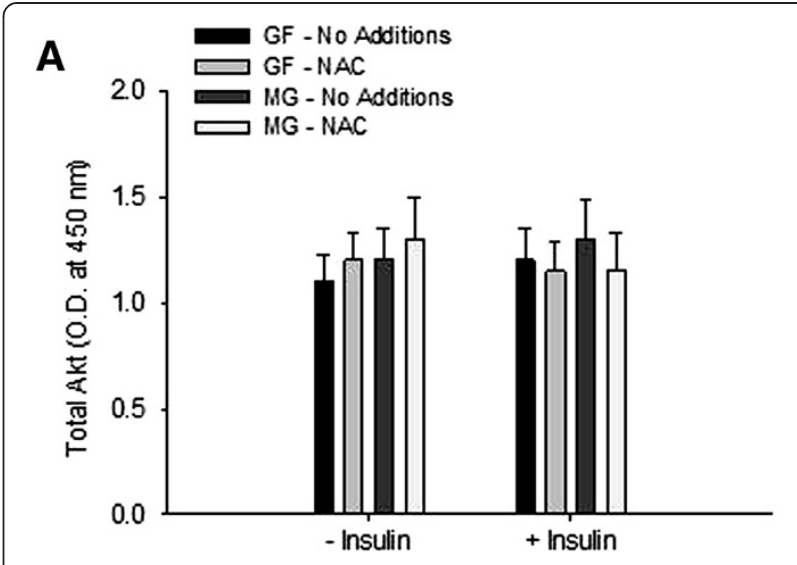

B

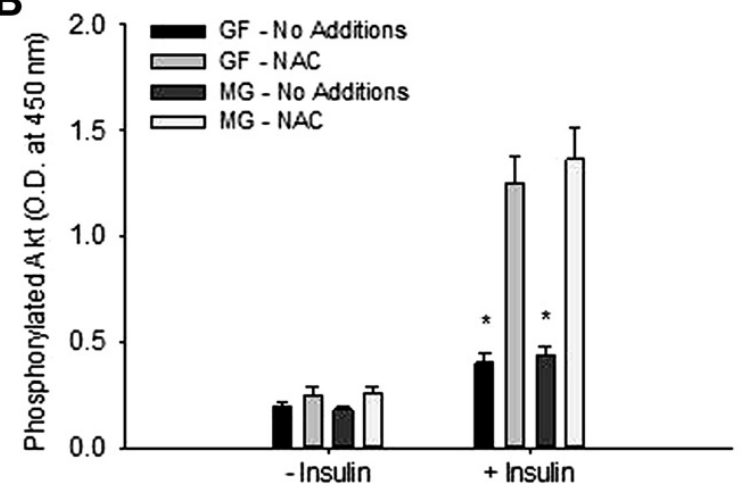

Figure 7 Effects of $\mathrm{N}$-acetyl cysteine on fructose- and methylglyoxal- mediated phosphorylation of Akt. Total (A) and phosphorylated (serine473) (B) Akt in primary hepatocytes incubated in the presence of fructose delivery (GF) or methylglyoxal in the media (MG) in the absence (No Additions) or presence of NAC $(20 \mathrm{uM})$. Data in graphs are the mean \pm SDEV for 4 independent experiments performed in triplicate. ${ }^{*}$ significantly different from No Additions $(p<0.05)$.

stress induced by fructose will ultimately depend on the concentration presented to the liver, the duration of exposure to increased fructose delivery, as well as multiple biologic and perhaps genetic factors $[8,39,40]$.

In the present study, we have examined the effects of physiologic concentrations of fructose on stress and insulin signaling in primary hepatocytes. Our results suggest that increase fructose delivery to hepatocytes modulates stress and insulin signaling. We hypothesize that fructose-mediated changes in methylglyoxal contribute to these acute effects.

\section{Abbreviations}

JNK: c-jun $\mathrm{NH}_{2}$-terminal kinase; IRS-1: Insulin receptor substrate-1; IRS-2: Insulin receptor substrate-2; MKK: Mitogen activated protein kinase kinase; NAC: N-acetyl cysteine; RPMI: Roswell Park Memorial Institute media.

\section{Competing interests}

The authors declare that they have no competing interests. 


\section{Authors' contributions}

YW and DW helped design experiments, carried out experiments, analyzed data, edited manuscript. GM, AE carried out experiments. MJP conceived of the studies, carried out experiments, analyzed data and wrote the manuscript. All authors read and approved the final manuscript.

\section{Acknowledgments}

This work was supported by NIH grants DK47416 and 072017 and the Lillian Fountain Smith Endowment

Received: 13 November 2012 Accepted: 1 April 2013

Published: 8 April 2013

\section{References}

1. Bleich SN, Wang YC: Consumption of sugar-sweetened beverages among adults with type 2 diabetes. Diabetes Care 2011, 34(3):551-555.

2. Malik VS, Schulze MB, Hu FB: Intake of sugar-sweetened beverages and weight gain: a systematic review. Am J Clin Nutr 2006, 84(2):274-288.

3. Pagliassotti MJ, Prach PA, Koppenhafer TA, Pan DA: Changes in insulin action, triglycerides, and lipid composition during sucrose feeding in rats. Am J Physiol 1996, 271(5 Pt 2):R1319-R1326.

4. Pagliassotti MJ, Shahrokhi KA, Moscarello M: Involvement of liver and skeletal muscle in sucrose-induced insulin resistance: dose-response studies. Am J Physiol 1994, 266(5 Pt 2):R1637-R1644.

5. Storlien LH, Kraegen EW, Jenkins AB, Chisholm DJ: Effects of sucrose vs. starch diets on in vivo insulin action, thermogenesis, and obesity in rats. Am J Clin Nutr 1988, 47:420-427.

6. Wei Y, Pagliassotti MJ: Hepatospecific effects of fructose on c-jun $\mathrm{NH}_{2}$ terminal kinase: implications for hepatic insuliin resistance. Am J Physiol Endocrinol Metab 2004, 287:E926-E933.

7. Dirlewanger $M$, Schneiter $P$, Jequier $E$, Tappy L: Effects of fructose on hepatic glucose metabolism in humans. Am J Physiol Endocrinol Metab 2000, 279:E907-E911.

8. Bizeau ME, Pagliassotti MJ: Hepatic adaptations to sucrose and fructose. Metabolism 2005, 54(9):1189-1201.

9. Lin A: Activation of the JNK signaling pathway: breaking the brake on apoptosis. Bioessays 2002, 25:17-24.

10. Zhang $Y$, Chen F: Reative oxygen species (ROS), troublemakers between nuclear factor-KB and c-jun $\mathrm{NH}_{2}$-terminal kinase. Cancer Res 2004, 64:1902-1905

11. Takagi Y, Du J, Ma XY, Nakashima I, Nagase F: Phorbol 12-myristate 13-acetate protects Jurkat cells from methylglyoxal-induced apoptosis by preventing c-Jun $\mathrm{N}$-terminal kinase-mediated leakage of cytochrome $\mathrm{c}$ in an extracellular signal-regulated kinase-dependent manner. Mol Pharmacol 2004, 65(3):778-787.

12. Berry M, Friend D: High-yield preparation of isolated rat liver parenchymal cells. A biochemical and fine structural study. J Cell Biol $1969,43: 506-519$.

13. Phillips J, Henly D, Berry M: Long-term maintenance of low concentrations of fructose for the study of hepatic glucose phosphorylation. Biochem J 1999, 337:497-501.

14. Brosnan MJ, Chen L, Wheeler CE, Van Dyke TA, Koretsky AP: Phosphocreatine protects ATP from a fructose load in transgenic mouse liver expressing creatine kinase. Am J Physiol Cell Physiol 1991, 260:C1191-C1200.

15. Masson S, Henriksen O, Stengaard A, Thomsen C, Quistorff B: Hepatic metabolism during constant infusion of fructose: Comparative studies with 31P-magnetic resonance spectroscopy in man and rats. Biochim Biophys Acta 1994, 1199:166-174.

16. Wei Y, Wang D, Pagliassotti MJ: Fructose selectively modulates c-jun $\mathrm{N}$-terminal kinase activity and insulin signaling in rat primary hepatocytes. J Nutr 2005, 135(7):1642-1646.

17. Chaplen FW, Fahl WE, Cameron DC: Method for determination of free intracellular and extracellular methylglyoxal in animal cells grown in culture. Anal Biochem 1996, 238(2):171-178.

18. Halliwell $B$, Whiteman M: Measuring reactive species an doxidative damage in vivo and in cell culture: how should you do ti and what do the results mean? Br J Pharmacol 2004, 142:231-255.

19. Gentile $C L$, Nivala AM, Gonzales JC, Pfaffenbach KT, Wang D, Wei Y, Jiang $H$, Orlicky DJ, Petersen DR, Pagliassotti MJ, et al: Experimental evidence for therapeutic potential of taurine in the treatment of nonalcoholic fatty liver disease. Am J Physiol Regul Integr Comp Physiol 2011 301(6):R1710-R1722.

20. Shimabukuro M, Zhou Y-T, Levi M, Unger RH: Fatty acid-induced B cell apoptosis: A link between obesity and diabetes. Proc Natl Acad Sci USA 1998, 95:2498-2502.

21. Wei Y, Wang D, Topczewski F, Pagliassotti MJ: Saturated fatty acids induce endoplasmic reticulum stress and apoptosis independently of ceramide in liver cells. Am J Physiol Endocrinol Metab 2006, 291:E275-E281.

22. Ruvolo PP: Intracellular signal transduction pathways activated by ceramide and its metabolites. Pharmacol Res 2003, 47(5):383-392.

23. Kurinna SM, Tsao CC, Nica AF, Jiffar T, Ruvolo PP: Ceramide promotes apoptosis in lung cancer-derived A549 cells by a mechanism involving c-Jun NH2-terminal kinase. Cancer Res 2004, 64(21):7852-7856.

24. Kaneto $H$, Matsuoka TA, Nakatani Y, Kawamori D, Miyatsuka T, Matsuhisa M, Yamasaki Y: Oxidative stress, ER stress, and the JNK pathway in type 2 diabetes. J Mol Med (Berl) 2005, 83(6):429-439.

25. Mendelson KG, Contois L-R, Tevosian SG, Davis RJ, Paulson KE: Independent regulation of JNK/p38 mitogen-activated protein kinases by metabolic oxidative stress in the liver. Proc Natl Acad Sci USA 1996, 93:12908-12913.

26. Xiao C, Giacca A, Lewis GF: Oral taurine but not N-acetylcysteine ameliorates NEFA-induced impairments in insulin sensitivity and beta cell function in obese and overweight, non-diabetic men. Diabetologia 2007, 51:139-146.

27. Riboulet-Chavey A, Pierron A, Durand I, Murdaca J, Giudicelli J, Van Obberghen E: Methylglyoxal impairs the insulin signaling pathways independently of the formation of intracellular reactive oxygen species. Diabetes 2006, 55(5):1289-1299.

28. Wei $Y$, Wang D, Topczewski F, Pagliassotti MJ: Fructose-mediated stress signaling in the liver: implications for hepatic insulin resistance. J Nutr Biochem 2007, 18(1):1-9.

29. Gulbins E, Li PL: Physiological and pathophysiological aspects of ceramide. Am J Physiol Regulatory Integrative Comp Physiol 2005, 290:R11-R26.

30. Beisswenger PJ, Drummond KS, Nelson RG, Howell SK, Szwergold BS, Mauer M: Susceptibility to diabetic nephropathy is related to dicarbonyl and oxidative stress. Diabetes 2005, 54(11):3274-3281.

31. Beisswenger PJ, Howell SK, Touchette AD, Lal S, Szwergold BS: Metformin reduces systemic methylglyoxal levels in type 2 diabetes. Diabetes 1999 48:198-202.

32. Davidoff AJ, Mason MM, Davidson MB, Carmody MW, Hintz KK, Wold LE, Podolin DA, Ren J: Sucrose-induced cardiomyocyte dysfunction is both preventable and reversible with clinically relevant treatments. Am $J$ Physiol Endocrinol Metab 2004, 286:E718-E724.

33. Jia $X$, Wu L: Accumulation of endogenous methylglyoxal impaired insulin signaling in adipose tissue of fructose-fed rats. Mol Cell Biochem 2007, 306(1-2):133-139.

34. Wang H, Meng $\mathrm{QH}$, Chang T, Wu L: Fructose-induced peroxynitrite production is mediated by methylglyoxal in vascular smooth muscle cells. Life Sci 2006, 79:2448-2454.

35. Wang $X$, Jia X, Chang T, Desai K, Wu L: Attenuation of hypertension development by scavenging methylglyoxal in fructose-treated rats. J Hypertens 2008, 26(4):765-772.

36. Spruss A, Bergheim I: Dietary fructose and intestinal barrier: potential risk factor in the pathogenesis of nonalcoholic fatty liver disease. J Nutr Biochem 2009, 20(9):657-662.

37. Stanhope KL, Schwarz JM, Keim NL, Griffen SC, Bremer AA, Graham JL, Hatcher B, Cox CL, Dyachenko A, Zhang W, et al: Consuming fructosesweetened, not glucose-sweetened, beverages increases visceral adiposity and lipids and decreases insulin sensitivity in overweight/ obese humans. J Clin Invest 2009, 119(5):1322-1334.

38. Thresher JS, Podolin DA, Wei Y, Mazzeo RS, Pagliassotti MJ: Comparison of the effects of sucrose and fructose on insulin action and glucose tolerance. Am J Physiol Regul Integr Comp Physiol 2000, 279(4):R1334-R1340.

39. Pagliassotti MJ, Horton TJ: Sucrose, insulin action and biologic complexity. Recent Res Devel Physiol 2004, 2:337-353.

40. Fried SK, Rao SP: Sugars, hypertriglyceridemia, and cardiovascular disease Am J Clin Nutr 2003, 78(4):873S-880S.

doi:10.1186/1743-7075-10-32

Cite this article as: Wei et al: Fructose-induced stress signaling in the liver involves methylglyoxal. Nutrition \& Metabolism 2013 10:32. 